\title{
Eksplorasi Jamur Alkalotoleran dari Desa Sukolilo Barat, Kecamatan Labang, Kabupaten Bangkalan, Madura, Jawa Timur
}

\author{
Helga Lusiana, MG Isworo Rukmi dan Budi Rahardjo \\ Laboratorium Mikrobiologi Jurusan Biologi FSM Undip \\ E-mail : helga.panggabean@yahoo.com
}

\begin{abstract}
Mold exploration from limestone hills West Sukolilo village, District Labang, Bangkalan, Madura, East Java, conducted to found the alkalotolerant mold isolates and investigate their amylolytic, proteolytic, and cellulolytic activity. Mold isolation were done using spread plate and dilution method on PDA and CMA at pH 8.0, 9.0, and 10.0. Twenty-seven mold isolates have been found consist of four genus i.e. Aspergillus, Fusarium, Curvularia, and Trichoderma. The result of amylolytic test showed Trichoderma longibrachiatum (IMD-26) have the highest activity at $\mathrm{pH} 8$, while Fusarium sp 2 (IMD-24) showed the highest activity at $\mathrm{pH}$ 9. Aspergillus flavus (IMD-7) showed highest proteolytic activity at $\mathrm{pH} 8$, while Hyphomycete (IMD-27) showed the highest activity at $\mathrm{pH} 9$. The highest cellulolytic activity at $\mathrm{pH} 8$ showed by Trichoderma harzianum (IMD-25) and $\mathrm{pH} 9$ by Fusarium sporotrichoides (IMD-20).
\end{abstract}

Keyword : alkalotoleran mold, amylolytic, proteolytic, cellulolytic.

\begin{abstract}
Abstrak
Eksplorasi kapang dari salah satu bukit kapur di Desa Sukolilo Barat, Kecamatan Labang, Kabupaten Bangkalan, Madura, Jawa Timur dilakukan untuk mendapatkan isolat kapang alkalotoleran dan mengetahui aktivitas amilolitik, proteolitik, dan selulolitik isolat yang diperoleh. Isolasi kapang dilakukan dengan metode spread plate dan pengenceran pada medium PDA dan CMA pH 8.0, 9.0, dan 10.0. Dua puluh tujuh isolat kapang berhasil diisolasi yang terdiri dari genus Aspergillus, Fusarium, Curvularia, dan Trichoderma. Uji aktivitas enzim pada $\mathrm{pH} 8$ dan 9 menunjukkan Trichoderma longibrachiatum (IMD-26) mempunyai aktifitas amilolitik tertinggi pada $\mathrm{pH} 8$, sedangkan Fusarium sp 2 (IMD-24) menunjukkan aktifitas tertinggi pada pH 9. Aktivitas proteolitik tertinggi pada pH 8 ditunjukkan oleh isolat A. flavus (IMD-7) sementara pada pH 9 oleh Hyphomycete (IMD-27). Aktifitas selulolitik tertinggi pada $\mathrm{pH} 8$ oleh Trichoderma harzianum (IMD-25) sementara pH 9 oleh Fusarium sporotrichoides (IMD-20).
\end{abstract}

Kata kunci : kapang alkalotoleran, amilolitik, proteolitik, selulolitik.

\section{PENDAHULUAN}

Pulau Madura merupakan daerah yang terletak di ujung timur pantai utara pulau Jawa. Kondisi tanah di Madura secara umum termasuk kriteria tandus dan gersang serta memiliki kandungan kapur yang tinggi. Tanah dengan kandungan kapur tinggi di Madura terbentuk dalam bukit-bukit kapur (Hartini et al., 2003). Karakteristik utama jenis tanah kapur adalah pada ketersediaan air yang rendah dan tingginya $\mathrm{pH}$ tanah yang seringkali diatas tujuh (reaksi tanah cenderung alkalis). Berdasarkan kondisi tersebut, pulau Madura diduga menyimpan potensi alam berupa mikroorganisme yang sangat besar, terutama kapang yang bersifat alkalotoleran (Supriyadi, 2007).

Kapang merupakan organisme yang mikroskopik, sebagian besar dari spesies kapang yang telah diketahui bersifat saprofit, hidup pada berbagai tempat seperti tanah, makanan bahkan hidup pada organik mati (Gandjar et al., 2006). Kapang yang mampu hidup dalam tanah alkalis disebut kapang alkalotoleran. Kapang alkalotoleran dapat mensintesis enzim spesifik yang mampu aktif di kondisi alkalis dan enzim ini sangat penting dalam proses industri (Gadd, 2004). 
Tanah di daerah Madura yang diketahui bersifat alkalin karena keadaannya yang kering dan berkapur, merupakan salah satu sumber mikroorganisme potensial penghasil enzim alkalin. Penelitian ini bertujuan mendapatkan isolat kapang alkalotoleran yang mempunyai aktivitas amilolitik, proteolitik, dan selulolitik kapang dari Desa Sukolilo Barat, Kecamatan Labang, Kabupaten Bangkalan, Madura.

\section{METODE PENELITIAN}

Sampel tanah kapur diambil secara aseptik dari salah satu bukit kapur di Desa Sukolilo Barat, Kabupaten Bangkalan, Madura. Pengambilan sampel sedalam 8-10 cm. Sampel yang diambil terdiri dari 3 titik yang berbeda berjarak 2-3 m, masing-masing titik ditandai sebagai sampel tanah A, B, dan C.

Isolasi kapang dilakukan secara sebaran dan pengenceran pada media PDA dan CMA dengan $\mathrm{pH} \mathrm{8,9,10.} \mathrm{Inkubasi} \mathrm{dilakukan} \mathrm{pada} \mathrm{suhu}$ $31^{\circ} \mathrm{C}$ selama 7 hari.

Identifikasi dilakukan dengan mengamati morfologi makroskopik dan mikroskopik kultur berumur 7 hari pada medium MEA, hasil pengamatan dicocokkan dengan kunci identifikasi dikotomis Compendium Of Soil Fungi (Domsch et al., 1980), Pengenalan Kapang Tropik Umum (Gandjar et al., 1999), The Genus Aspergillus (Raper \& Fennel, 1965), dan Food and Indoor Fungi (Samson et al., 2010).

Pengujian aktivitas enzimatis meliputi ujiamilolitik menggunakan medium PDA yang ditambahkan Starch Soluble 1\%, uji proteolitik menggunakan medium Gelatin Broth 15\%, dan uji selulolitik menggunakan medium Carboxy Methyl Cellulose (CMC) Agar.

\section{HASIL DAN PEMBAHASAN}

Enam puluh satu isolat berhasil diisolasi dari tiga sampel tanah tanah kapur dari Desa Sukolilo, Bangkalan Madura, yang selanjutnya dapat dikelompokkan menjadi 27 isolat representatif, terdiri dari 17 isolat genus Aspergillus, meliputi 6 spesies section Nigri, 8 spesies section Flavi, 1 spesies section Fumigati, dan 2 spesies section Terrei, dan 6 spesies Fusarium, 2 spesies Trichoderma, 1 spesies Curvularia dan 1 spesies IMD-27 (Gambar 1). Seluruh isolat mampu hidup dalam pH 8-10, sehingga dapat digolongkan sebagai kapang alkalotoleran. 

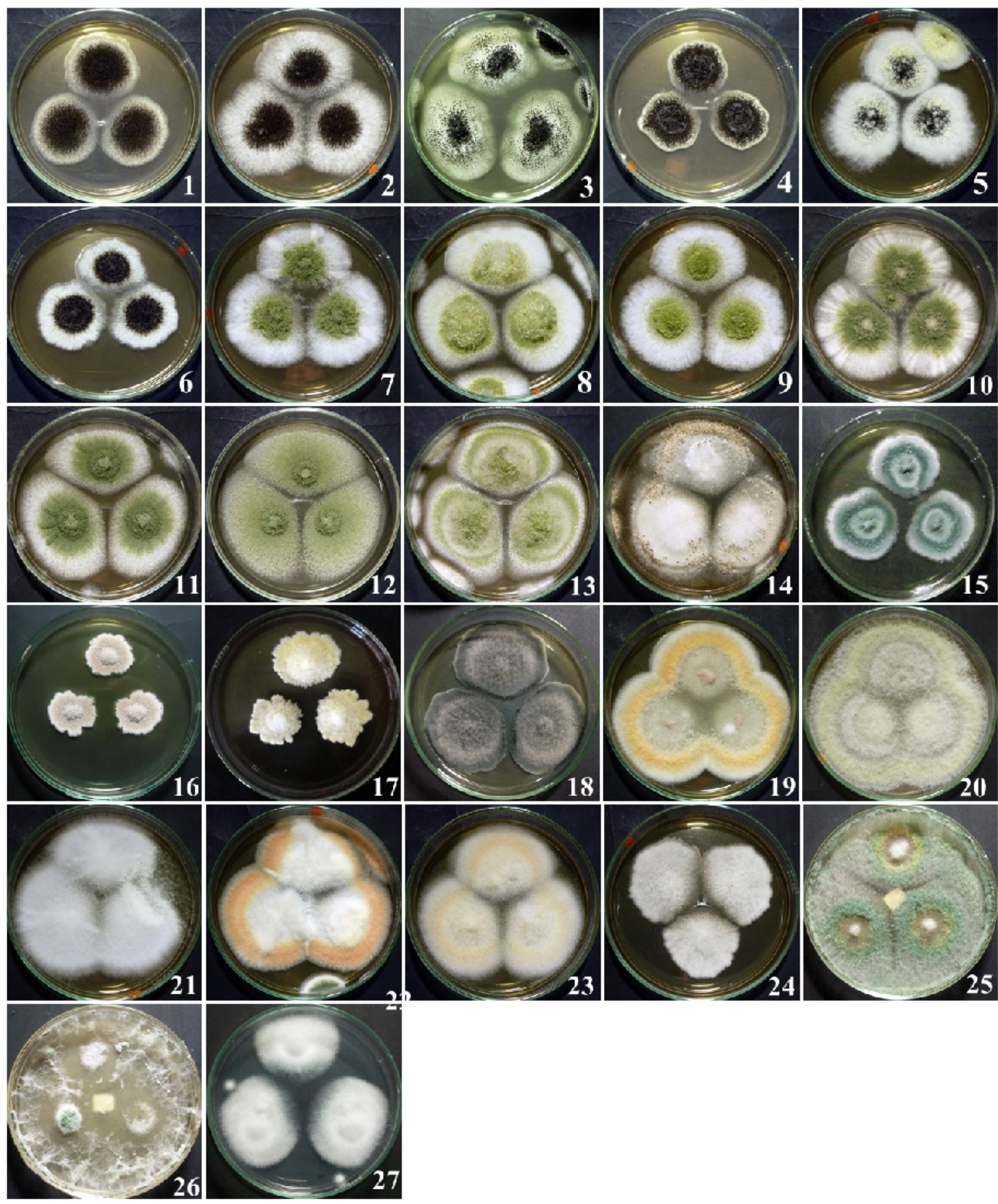

Gambar 1. Koloni isolat alkalotoleran pada medium MEA umur 7 hari. (1) A. niger (IMD-1), (2) A. awamori (IMD2), (3) A. phoenicis (IMD-3), (4) A. ficuum (IMD-4), (5) A. section Nigri 1 (IMD-5), (6) Aspergillus section Nigri 2 (IMD-6), (7) A. flavus (IMD-7), (8) A. subolivaceus (IMD-8), (9) A. flavo-furcatis (IMD9), (10) Aspergillus section Flavi 1 (IMD-10), (11) Aspergillus section Flavi 2 (IMD-11), (12) Aspergillus section Flavi 3 (IMD-12), (13) Aspergillus section Flavi 4 (IMD-13), (14) Aspergillus 
section Flavi 5 (IMD-14), (15) A. fumigatus (IMD-15). (16) A. terreus (IMD-16), (17) A. aureoterreus (IMD-17), (18) C.lunata (IMD-18), (19) F.chlamydosporum (IMD-19), (20) F. oxysporum (IMD-20), (21) F. sporotrichoides (IMD-21), (22) F. verticillioides (IMD-22), (23) Fusarium sp 1 (IMD-23), (24) Fusarium sp 2 (IMD-24), (25) T.harzianum (IMD-25), (26) T. longibrachiatum (IMD-26), (27) Hypomycete (IMD-27).

Tabel 1. Kehadiran kapang alkalotoleran pada sampel tanah kapur dan diameter koloni isolat kapang yang ditumbuhkan pada media CMA dengan $\mathrm{pH}$ yang berbeda.

\begin{tabular}{|c|c|c|c|c|c|c|c|c|}
\hline \multirow[b]{2}{*}{ Kode Isolat } & \multirow[b]{2}{*}{ Nama Isolat } & \multicolumn{3}{|c|}{ Sampel } & \multirow{2}{*}{$\begin{array}{c}\text { Kehadiran } \\
\text { Isolat Terhadap } \\
\text { Sampel }(\%)\end{array}$} & \multicolumn{3}{|c|}{ Diameter koloni (mm) } \\
\hline & & A & B & $\mathrm{C}$ & & $\mathrm{pH} 8$ & $\mathrm{pH} 9$ & $\mathrm{pH} 10$ \\
\hline IMD - 1 & Aspergillus niger & + & + & + & 100 & 78 & 65 & 8 \\
\hline IMD - 2 & Aspergillus awamori & + & + & - & 66,6 & 43 & 69 & 0 \\
\hline IMD - 3 & Aspergillus phoenicis & + & + & + & 100 & 90 & 65 & 6 \\
\hline IMD - 4 & Aspergillus ficuum & - & + & + & 66,6 & 42 & 70 & 6 \\
\hline IMD - 5 & Aspergillus section Nigri 1 & - & - & + & 33,3 & 89 & 65 & 8 \\
\hline IMD - 6 & Aspergillus section Nigri 2 & + & + & - & 66,6 & 90 & 69 & 0 \\
\hline IMD - 7 & Aspergillus flavus & + & + & + & 100 & 41 & 40 & 20 \\
\hline $\mathrm{IMD}-8$ & Aspergillus subolivaceus & + & + & + & 100 & 69 & 49 & 6 \\
\hline IMD - 9 & Aspergillus flavo-furcatis & + & + & + & 100 & 65 & 48 & 12 \\
\hline IMD - 10 & Aspergillus section Flavi 1 & - & + & + & 66,6 & 51 & 43 & 24 \\
\hline IMD - 11 & Aspergillus section Flavi 2 & + & + & - & 66,6 & 75 & 62 & 10 \\
\hline IMD - 12 & Aspergillus section Flavi 3 & - & + & + & 66,6 & 49 & 59 & 21 \\
\hline IMD - 13 & Aspergillus section Flavi 4 & - & + & + & 66,6 & 47 & 50 & 21 \\
\hline IMD -14 & Aspergillus section Flavi 5 & - & + & + & 66,6 & 74 & 64 & 25 \\
\hline IMD -15 & Aspergillus fumigatus & + & + & - & 66,6 & 70 & 47 & 21 \\
\hline IMD -16 & Aspergillus terreus & - & + & + & 66,6 & 48 & 49 & 21 \\
\hline IMD -17 & Aspergillus aureoterreus & + & + & + & 100 & 62 & 40 & 22 \\
\hline IMD -18 & Curvularia lunata & - & + & + & 66,6 & 42 & 34 & 33 \\
\hline IMD -19 & Fusarium chlamydosporum & - & + & - & 33,3 & 46 & 47 & 27 \\
\hline IMD -20 & Fusarium oxysporum & + & + & - & 66,6 & 46 & 37 & 16 \\
\hline IMD -21 & Fusarium sporotrichoides & - & - & + & 33,3 & 32 & 33 & 17 \\
\hline IMD -22 & Fusarium verticillioides & + & + & + & 100 & 45 & 37 & 24 \\
\hline IMD -23 & Fusarium sp 1 & - & + & - & 33,3 & 30 & 49 & 24 \\
\hline IMD -24 & Fusarium sp 2 & - & + & + & 66,6 & 51 & 38 & 22 \\
\hline IMD -25 & Trichoderma harzianum & + & + & + & 100 & 41 & 25 & 16 \\
\hline IMD -26 & Trichoderma longibrachiatum & + & + & + & 100 & 62 & 69 & 15 \\
\hline IMD -27 & Hyphomycete & + & - & + & 66,6 & 38 & 49 & 33 \\
\hline EJenis & olat & & 5 & 24 & 22 & & & \\
\hline
\end{tabular}

Menurut Manivannan \& Kathiresan (2007) kapang alkalotoleran adalah kapang yang $\mathrm{pH}$ untuk pertumbuhan optimalnya mendekati netral yaitu $\mathrm{pH}$ 8. Pada penelitian ini seluruh isolat dapat tumbuh baik pada $\mathrm{pH} 8$ (Tabel 1), sehingga kemungkinan isolat-isolat tersebut merupakan galur alkalotoleran terutama kelompok Aspergillus section Flavi, Fusarium, Trichoderma, dan satu spesies hypomycetes. Genus Aspergillus, diketahui sebagai kapang yang umum dijumpai pada tanah salin. Coral (2003) menemukan A. niger yang dapat hidup yang cukup baik pada $\mathrm{pH} 8$ 9. 
Spesies dari genus Fusarium cukup banyak dilaporkan kehadirannya pada tanah alkalin. Nagai et al. (1998) berhasil mengisolasi Fusarium dari tanah dengan kisaran pH 6 sampai 9, Kladwang (2003) juga berhasil mengisolasi Fusarium sp. yang tumbuh optimal pd pH 8 sampai 9 dari tanah kapur di Thailand. Genus Trichoderma juga dikenal sebagai salah satu kapang yang mampu hidup pada $\mathrm{pH}$ tinggi. Arenas et al. (2012) melaporkan Trichoderma mampu tumbuh pada $\mathrm{pH}$ 9, namun pada $\mathrm{pH} 10$ mengalami penurunan diameter koloni yang cukup besar. Trichoderma dapat di isolasi dari tanah, biji-bijian, rhizosfer kentang, serta kayu dan memiliki suhu pertumbuhan optimum $15^{\circ} \mathrm{C}-35^{\circ} \mathrm{C}$.

Tabel 2 menunjukkan parameter lingkungan tanah saat pengambilan sampel dapat dilihat pada. Sampel B memiliki $\mathrm{pH}$ lingkungan tertinggi dan paling banyak ditemukan spesies kapang yang berbeda. $\mathrm{pH}$ tanah dapat mempengaruhi kelarutan unsur hara di dalam tanah (Rao, 1994), . tanah yang netral atau basa dapat lebih melarutkan unsur hara daripada tanah yang asam. Kelarutan unsur hara yang tinggi dalam tanah akan mempermudah mikroorganisme tanah menggunakan unsur hara tersebut, sehingga semakin banyak spesies dapat hidup

Tabel 2. Faktor-faktor lingkungan lokasi pengambilan sampel

\begin{tabular}{ccccccc}
\hline \multirow{2}{*}{ Sampel } & \multirow{2}{*}{$\mathrm{pH}$} & \multirow{2}{*}{$\begin{array}{c}\text { Suhu } \\
\left({ }^{\circ} \mathrm{C}\right)\end{array}$} & Kelembapan & $\begin{array}{c}\text { Ketinggian } \\
(\mathrm{mdpl})\end{array}$ & & \multicolumn{2}{c}{ Posisi } \\
\cline { 6 - 7 } & & 30 & 1 & 23 & $112^{\circ} 50^{\prime} 12.4^{\prime \prime}$ & $-7^{\circ} 9^{\prime} 42.819^{\prime \prime}$ \\
$\mathrm{A}$ & 7,2 & 30 & 1 & 23 & $112^{\circ} 50^{\prime} 12.8^{\prime \prime}$ & $-7^{\circ} 9^{\prime} 42.884^{\prime \prime}$ \\
$\mathrm{B}$ & 7,8 & 30 & 1 & 23 & $112^{\circ} 50^{\prime} 12.6^{\prime \prime}$ & $-7^{\circ} 9^{\prime} 42.751^{\prime \prime}$ \\
\hline
\end{tabular}

\section{Uji Enzimatis Isolat}

Kehadiran kapang di dalam tanah selalu berhubungan dengan perannya sebagai agen biodegradasi, yang dapat membantu ketersediaan nutrisi dan meningkatkan unsur hara didalam tanah. Kapang di dalam tanah berperan penting dalam siklus biogeokimiawi di alam, karena mampu menguraikan berbagai bahan organik dengan bantuan berbagai enzim yang disintesisnya (Valentin, 2006).

Hasil pengamatan terhadap aktivitas amilolitik isolat kapang dari tanah kapur menunjukkan bahwa, tidak semua isolat kapang yang diperoleh mampu menghidrolisi amilum (Gambar 2.). Aktifitas amilolitik tertinggi ditunjukkan oleh $T$. longibrachiatum (IMD-26) dan Aspergillus section Flavi 3 (IMD-13), baik pada $\mathrm{pH} 8$ maupun $\mathrm{pH} 9$ dan aktivitas amilolitik tertinggi pada pH 9 oleh Fusarium sp 2 (IMD-24). Aktivitas amilolitik dari semua isolat mengalami penurunan pada $\mathrm{pH}$ 9, Behal et al., (2006) menyatakan bahwa $\mathrm{pH}$ optimum untuk aktivitas $\alpha$ - amilase adalah 8. Aktivitas amilolitik pada $\mathrm{pH} 8$ dari semua isolat lebih tinggi dari aktivitas pada $\mathrm{pH}$ 9. Meskipun semua isolat mampu tumbuh namun beberapa tidak menunjukkan zona hidolisis. Varalaksmi (2009), mengatakan isolatisolat tersebut kemungkinan dapat menghasilkan enzim amilase dengan aktifitas yang sangat kecil, sehingga tidak terukur atau teramati.

Uji aktivitas proteolitik terhadap isolatisolat dari tanah kapur menunjukkan hasil yang beragam (Gambar 3). Aktivitas proteolitik tertinggi ditunjukkan oleh Aspergillus flavus pada pH 8 dan terlihat masih cukup stabil pada $\mathrm{pH} 9$. Selain itu aktivitas proteolitik yang cukup tinggi di tunjukkan oleh kelompok Aspergillus section Flavi dan beberapa isolat Genus Fusarium dan Trichoderma. Secara keseluruhan aktivitas proteolitik cenderung menurun pada $\mathrm{pH}$ 9, dibandingkan dengan $\mathrm{pH}$ 8. Penelitian tentang alkaline protease yang dilakukan oleh Rani et al. (2012), menunjukkan bahwa aktivitas proteolitik optimum kelompok Aspergillus section Flavi 
terjadi pada $\mathrm{pH}$ 8,5. Kelompok Aspergillus section Flavi dalam penelitian ini masih menunjukkan aktivitas proteolitik pada $\mathrm{pH} 8$ dan 9. Isolat genus Trichoderma menunjukkan aktivitas proteolitik yang lebih besar pada $\mathrm{pH} 9$ dibandingkan $\mathrm{pH} 8$. Protease dari kapang dapat aktif pada kisaran $\mathrm{pH}$ yang luas ( $\mathrm{pH} 4$-11) (Coral, 2003), tetapi memiliki toleransi terhadap panas yang lebih kecil dibandingkan protease pada bakteri. Protease alkalis pada kapang secara umum berjenis serine protease, yang aktif pada $\mathrm{pH}$ netral dan alkaline dengan $\mathrm{pH}$ optimum antara $\mathrm{pH} 7$ sampai 11. Isolat Trichoderma dalam penelitian ini menunjukkan aktifitas protease yang lebih baik pada $\mathrm{pH}$ 9, sehingga ada kemungkinan bahwa $\mathrm{pH}$ optimum protease pada genus ini lebih dari 8

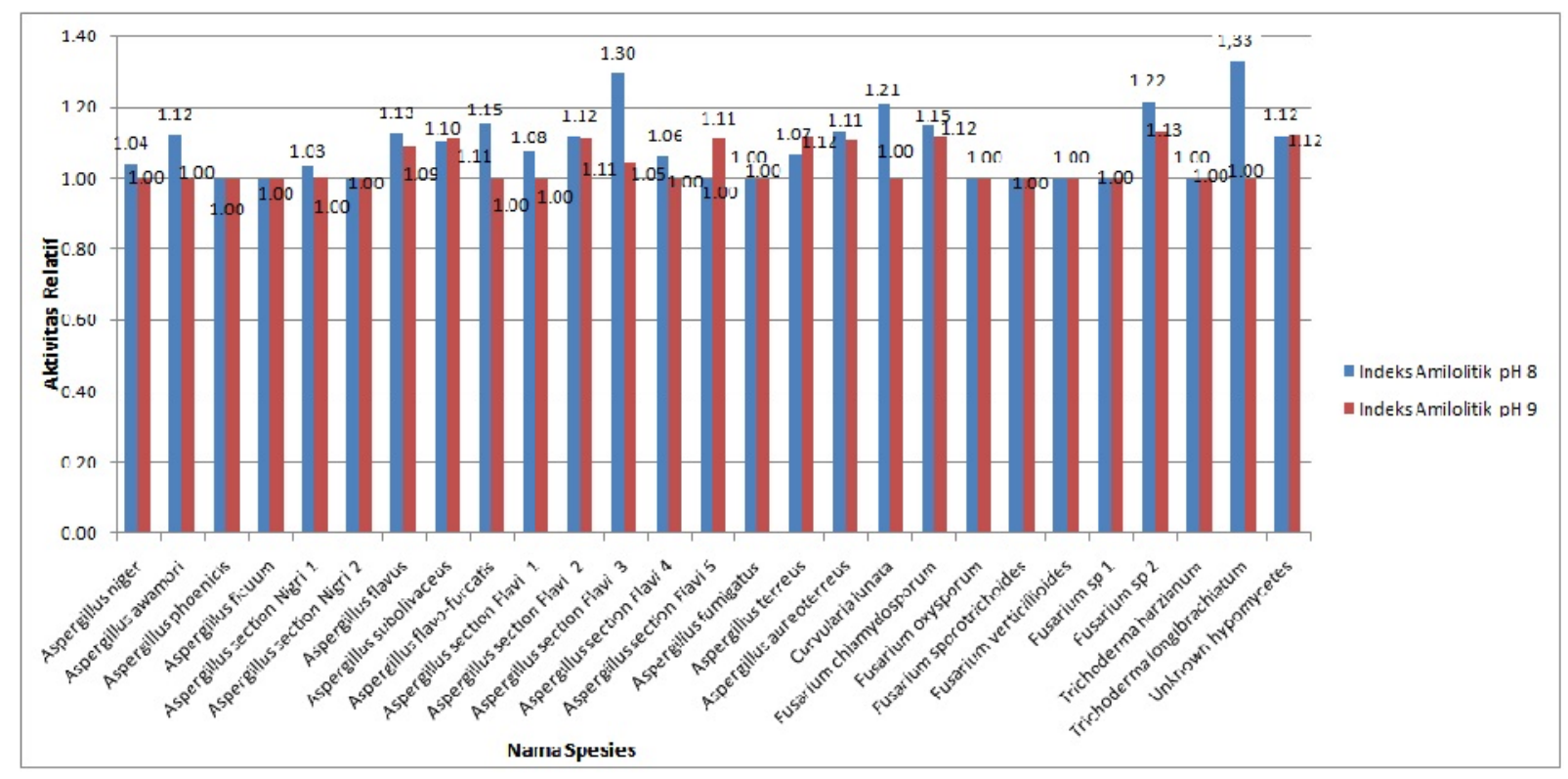

Gambar 2. Indeks amilolitik isolat kapang alkalotoleran pada dua $\mathrm{pH}$ yang berbeda

Uji aktivitas selulolitik menunjukkan bahwa beberapa isolat tidak menunjukkan aktivitas selulolitik baik pada pH 8 maupun $\mathrm{pH} 9$ (Gambar 4). Aktivitas selulolitik tertinggi pda $\mathrm{pH} 8$ ditunjukkan oleh isolat $T$. harzianum (IMD-25) namun pada $\mathrm{pH} 9$ aktivitas selulolitiknya sangat kecil (Gambar 3), Salma dan Gunarto (1999) menemukan Trichoderma memiliki kemampuan menghidrolisis selulosa dengan baik pada kondisi alkalin sehingga sering disebut selulolitik sejati. Isolat Fusarium sp 2 (IMD-24) menunjukkan aktivitas selulolitik yang juga cukup tinggi dan, cukup stabil pada $\mathrm{pH} 8$ dan 9. Aktivitas selulolitik tertinggi pada $\mathrm{pH} 9$ ditunjukkan oleh isolat $F$. sporotrichoides (IMD-21) di ikuti isolat Fusarium sp.1 (IMD-24) dan Fusarium sp.2 (IMD-24). Aktivitas selulolitik dari kelompok Fusarium sp. cenderung meningkat pada $\mathrm{pH}$ yang lebih tinggi, hal ini menunjukkan kemungkinan Fusarium sp. dan Trichoderma sp. merupakan galur alkalotoleran. Beberapa isolat dari tanah Madura khususnya black aspergili ternyata mampu tumbuh pada medium Carboxymethyl cellulose (CMC) yang digunakan untuk uji selulolitik, namun tidak menunjukkan adanya zona hidrolisis, hal ini dapat disebabkan karena kemampuan produksi selulase dari isolat tersebut sangat rendah. Purwadaria (2003) mengatakan bahwa kapang-kapang yang menghasilkan enzim selulase dengan aktivitas yang sangat kecil akan menghasilkan zona bening yang tidak terlihat jelas atau mungkin hanya terdapat di bawah koloni sehingga tidak mudah diamati. 


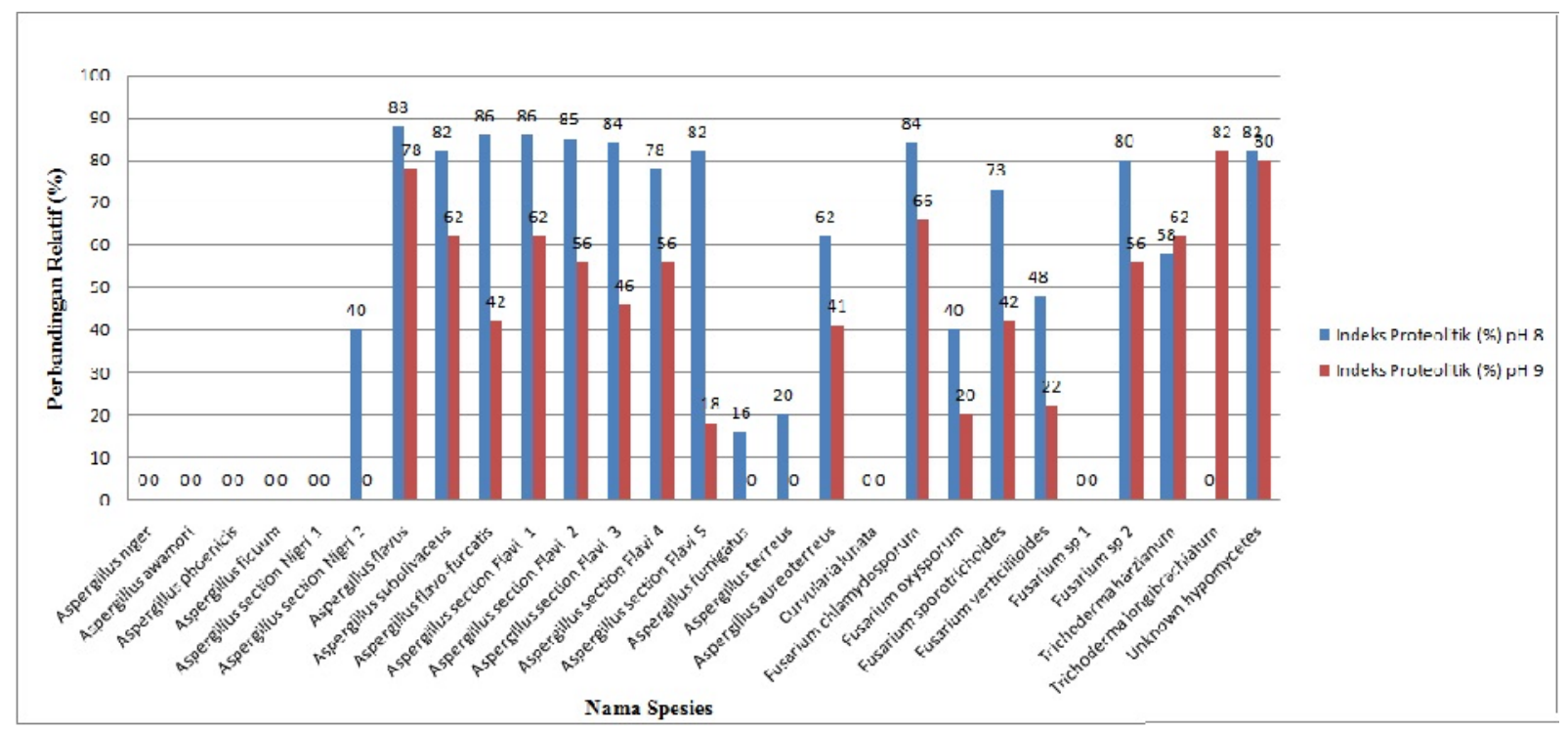

Gambar 3. Indeks proteolitik isolat kapang alkalotoleran pada dua $\mathrm{pH}$ yang berbeda.

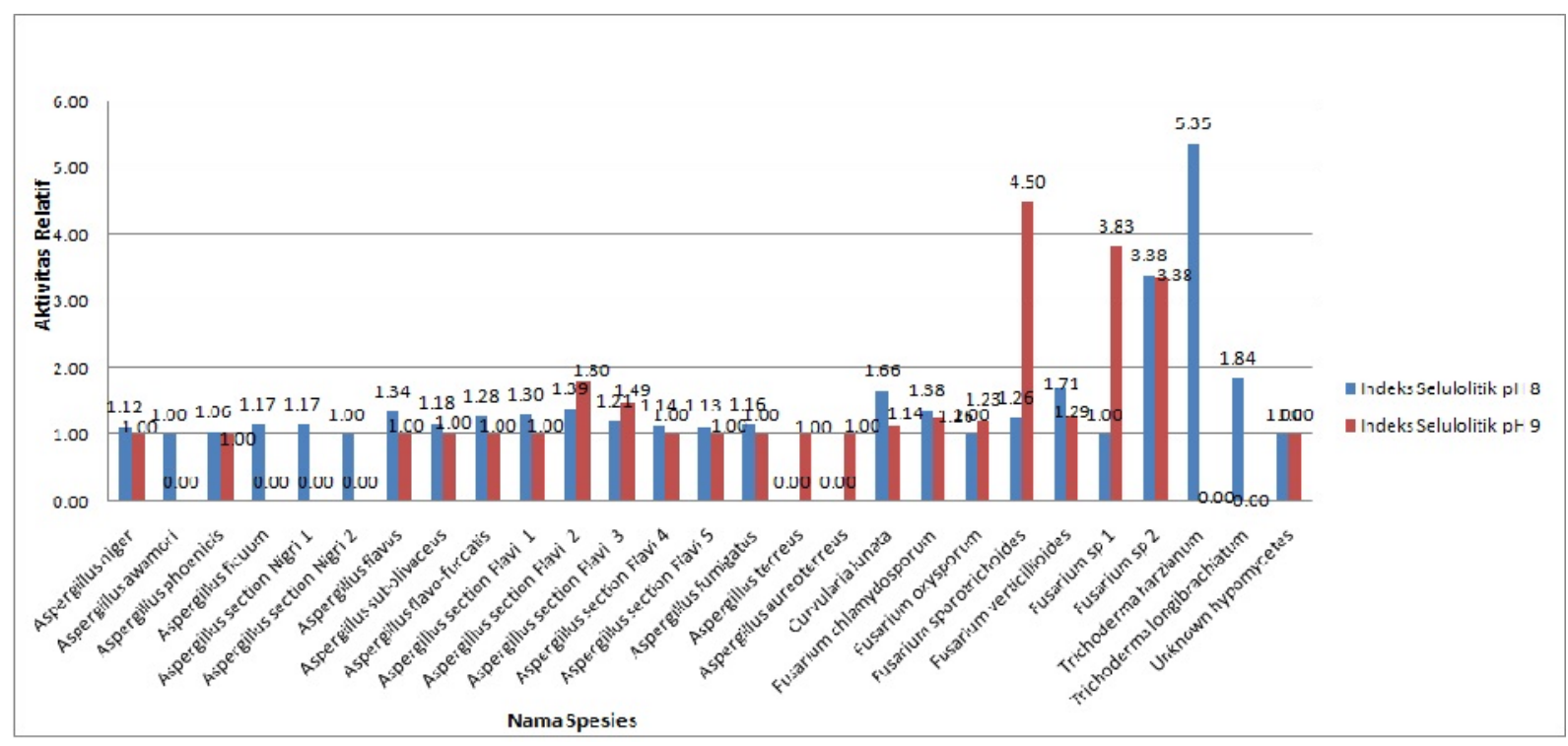

Gambar 4. Indeks selulolitik isolat kapang alkalotoleran pada dua $\mathrm{pH}$ yang berbeda.

\section{KESIMPULAN}

Dua puluh tujuh isolat kapang alkalotoleran berhasil ditemukan pada tanah kapur dari Desa Sukolilo Barat, Kecamatan Labang, Kabupaten Bangkalan, Madura, yang terdiri dari genus Aspergillus, Fusarium, Trichoderma, Curvularia dan satu jenis Hyphomycete.. Sebagian besar isolat menunjukkan aktivitas amilolitik, proteolitik, dan selulolitik. Aktivitas amilolitik tertinggi pada $\mathrm{pH} 8$ ditunjukkan oleh isolat $T$. longibrachiatum (IMD26), sementara pada $\mathrm{pH} 9$ ditunjukkan oleh isolat Fusarium sp 2 (IMD-24). Isolat A. flavus (IMD-7) menunjukkan aktivitas proteolitik tertinggi pada $\mathrm{pH} 8$ dan $\mathrm{pH}$ 9. Aktivitas selulolitik tertinggi pada pH 8 ditunjukkan oleh isolat T.harzianum (IMD- 
25), sementara pada $\mathrm{pH} 9$ ditunjukkan oleh isolat F. sporotrichoides (IMD-20).

\section{DAFTAR PUSTAKA}

Arenas,O.R., Huato, M.A.D., Treviño, I.H. Lezama, J.F.C.P., García, A.A. \& Arellano, A.D.V. 2012. Effect of $\mathrm{pH}$ on Growth of the Mycelium of Trichoderma Viride and Pleurotus Ostreatus in Solid Cultivation Mediums. Afr. J. Agri. Res., 7 (34) : 4724 4730.

Eliades, L.A., Cabello M.N. \& Voget C.E. 2006. Contribution To The Study Of Alkalofilik and Alkali-Tolerant Ascomycota From Argentina. Darwiniana 44(1): 64-73.

Gadd, M. G. 2004. Mycotransformation Of Organic And Inorganic Substrates. Mycologist 18: 60-70.

Gandjar, I., Sjamsuridzal, W. \& Oetari, A. 2006. Mikologi Dasar dan Terapan. Yayasan Obor Indonesia. Jakarta.

Hartini, S., Suprajaka, Rahardjati, A., Saputro, G.B. \& Marschiavelli, M.I.C. 2003. Kajian Wilayah Pulau Madura dan Kepulauan Kangean. Pusat Survei Sumberdaya Alam Laut BAKOSURTANAL, Bogor.

Ismail, A., Mazen, M.B. \& Saber, S.M. 1984. Some Enzymatic Activitiesof Fungi Isolated from Cotton Seed Products. Biosci, 4 : 8593.

Kasana, R.C., Salwan, R., Dhar, H., Dutt, S. \& Gulati, A. 2008. A rapid and easy method for detection of microbial cellulases on agar plates using Gram's iodine. Curr. Microbiol, 57 : 503-507.

Kladwang, W., Bhumirattana, A. \& Hywel-Jones, N. 2003. Alkaline-Tolerant Fungi from Thailand. Fungal Divers., 69-84.

Manivannan, S. \& Kathiresan, K. 2007. Production of Alkaline Protease by Streptomyces sp., Isolated from Coastal Mangrove Sediment. Res. J. Environ. Sci. 1: 173-178.

Mubarik, N.R., Damayanti, E., \& Listyowati, S. 2003. Isolasi dan Karakterisasi Amilase dari Kapang Alkalotoleran Asal Limbah Cair Tapioka. Biota VIII (1) : 1-8.

Nagai, K., Suzuki, K. \& Okada, G. 1998. Studies on the Distribution of Alkalophilic and Alkalo-tolerant Soil Fungi II : Fungal Flora in Two Limestone Caves in Japan. Mycoscie, 39 :293-298.

Purwadaria, T., Marbun P. A., Sinurat A. P. \& Ketaren P. P. 2003. Perbandingan Aktivitas Enzim Selulase dari Bakteri dan Kapang Hasil Isolasi dari Rayap. JITV 8(4): 213-219

Samson, R.A., Houbraken, J., Thrane, U., Frisvad, J.C. \& Andersen, B. I 2010. Food and Indoor Fungi. CBS-KNAW Fungal Biodiversity Centre Uthrect, Netherlands. Supriyadi, S. 2007. Kesuburan Tanah di Lahan Kering Madura. Embryo 4(2): 124-131. 